TO:. Mr. Edzo Tonkes

The Bernard van Leer Foundation

P.0. Box 82334

$2508 \mathrm{EH}$ The Hague

The Netherlands

FroM: Nancy Hatch Dupree

Executive Director

ACBAR Resource and Information Centre

P.O. Box 860

Peshawar

Pakistan

DATE: 28 May 1990

SUBJECT:. Second Evaluation of the Mother-Child Centre Programme for Afghan Refugees, Pakistan; undertaken January thru May 1990

\title{
SUMMARY OF EVALUATION
}

* The MCC Programme for Afghan Refugees provides a solid base for future innovative programming.

- The personnel and management training, enhanced through seminars and workshope, has provided an excellent core resource. Methods focusing on ways to identify priorities based on reeds assessments, including data-recording systems to facilitate studies of participant backgrounds and motivations, is an essential next step.

- The development of written resources and legrning aids continues to be a key component.

- MCC concepts seem best suited to urban communities, but the current rural programmes are providing interesting data which could lead to important ingights into development methodology.

- Itaff shortages inhibit the exploration of new possibilities and dimensions. 


\section{EVALUATION DESIGN}

\section{$\underline{\text { Pages }}$}

INTRODUCTION

Current Attitudes Toward Women 3

Structure of the Evaluation 5

ANALYSES OF OBJECTIVES

Rural Populations: Kahi 7

Shin Dand 12

Urban Programme: Feshawar 18

MANAGEMENT DEVELOPMENT 24

MOVEMENT TOWARD WHAT GOAL 26

MAJOR SUGGESTIONS 31 


\section{INTRODUCTION}

\section{Current Attitudes Towerd Women}

This second evaluation is written during a time of tension while a cempaign touting two major themes plays on the raw emotions of the refugees in the Peshawar area. One allegation claims that humanitarian assistance is merely a guise for dangerous westernization, that is, Afghanistan is about to be engulfed by cultural imperialism, and the other rails against evil permlssive western practices that threaten Islamic values regarding women.

It is as yet unclear who may be orchestrating this hostile assault; nor is their purpose easily perceptible. It would appear, however, that the ultimate design involves wider political strategies in the struggle for power inside Afghanistan and that the perpetrators are attempting to enhance their prospects by exploiting the two most sensitive issues guaranteed to provoke mob reaction, instill fear and foment confusion.

As regards women, facilities for women supported by foreign assistance organizations have been attacked, burned and looted; Afghan women working with organizations funded by foreign monies have been served with warnings to quit or bear the consequences.

A sampling of the rhetoric used in the widely-distributed Pashto, Dari and English leaflets includes such unsettling 
The individuals involved in distributing this hate Iiterature are for the most part young, one-time mujahidin and it has been suggested that these youth are now bereft of a cause, bored, unable to adjust to structured productive activities, and simply out of control.

It has been all too evident for some time that the political parties command little respect and these activities can certainly be seen as an unfortunate manifestation of this lack of leadership. However, lack of overall control does not preclude the fact that a higher scenario exists; there is reason for grave concern.

This said, it remains to be emphasized that these events are most probably a passing phase which will largely dissipate once a satisfactory final settlement for Afghanistan is attained. Many Afghan men are highly disturbed. "What is happening to us?," they ask. It behooves those sincerely interested in Afghanistan's future, therefore, to continue providing support -- discreet support. The women who now battle this distortion of Afghan culture display the most remarkable courage -- and they deserve every encouragement. Now is not the time to desert them.

\section{Structure of the Evaluation}

As with the first evaluation (Kahi; January 1989), this discussion emphasizes qualitative assessments focusing on the 
cultural appropriateness of the MCC programmes, without reference to much quantatative data, which, in fact, only minimally exist. The evaluator has, however, maintained a sustained close relationship with the programme since its inception, visiting the projects regularly, consulting with the staff on all levels and participating in seminars and workshops.

Summative rather than formative, the evaluation provides up-dates on key recommendations included in the first evaluation and discusses what has been achieved in meeting major objectives. By drawing attention to lessons extracted from the programme, an overall perception of possible future programming emerges. These are included in the final discussion.

The choosen objectives of individual projects are: Kahi Camp Mother-Child Centre Project (Hungu) (See Objectives 1 thru 4; pgs.1 - 12)

- provide practical health and child-care education to children

- enhance developmental abilities in children

- support the special role of older children in caring for younger siblings

- reinforce cultural identity

Shin Dand Camp Mother-Child Centre Project (Kohat) (See Objectives 1 thru 5; pgs.15-18)

- introduce objectives similar to Kahi

- encourage constructive interactive play/learning activities for mothers and their children 
Early Childhood Education Training Project (Peshawar)

(See Objectives I thru 4; pgs.19-2.3)

- develop a training and resource centre with practical facilities to support women caregivers

- develop written sources and learning aids

- provide support to the rural projects and related organizations outside the MCC Programme

- provide outreach support to trainees wishing to establish early childhood education projects

\section{ANALYSES OF OBJECTIVES}

Rural Populations: Kahi, opened April 1988

Participants. The daily attendance of from 40-100 boys and girls, aged 6 months to 13 years, continues to consist mainly of preteens, usually accompanied by younger siblings. The older children are largely short-time visiting school boys whose high spirits are infectious, but disciplined. They participate energetically and competently in the more structured activities, such as the health and mine awareness lessons which provide excellent language skill development and leaderbhip experience.

No methods have yet been devised for recording the number attending regularly, sporadically or occasionally, nor have background profiles been collected. The conatraints on the staff are acknowledged, but serious approaches to eliciting these types of data will be essential if postrepatriation programmes are envisioned. 
The motivation of the attendees is also not clearly defined. Do children come in while they wait for mothers visiting the health units, are they from neer-by homes, do they come mainly for the milk, fruit and other occasional handouts? An increase in attendance occurs during such distributions and it is surmised that these children will inevitably return, but is this in fact so?

\section{Activ1ties: Objectives 1 and 2: health education and development activities}

It is notably evident that the children are now involved in the learning processes more than they were before. A new structured schedule of activities contributes to this, but, more particularly, the staff now mekes a concerted effort to encourage children to speak out and take part in the lessons and storytelling. Whether this increase in participation extends the benefits of the lessons into individual households is impossible to say for house visits have yet to be organized because of a shortage of staff and the difficulties women experience in moving freely within the camp. Nevertheless, this is another key consideration for future programming.

In addition to strengthening learning abilities, the increased use of participatory techniques has given the children more self-confidence and emotional security. This would suggest that further development of the excellent 
visual materials already being used would reap rich benefits. Particularly worthy of note are the sets of colourfully illustrated storycards which have been laminated for durability. Sets of these donated by MCC to ARIC (ACBAR Resource and Information Centre) have been well-received by the assistance community in Peshawar. More are requested. Added selections, increased production and wider distribution is indicated. This will be of paramount importance after repatriation as well, for while the paucity of such materials in prewar Afghanisten was lamentable, the need will be even more urgent in the years to come.

An important step in this direction was made with the cooperation of Professor Margaret Mills from The University of Pennsylvania who produced an excellent paper outlining how storytelling develops the use of memory as well as an understanding of morals, ethics and religion, while encouraging imaginative approaches to life. Methods for utilizing six categories of stories are explained, together with storytelling techniques. The paper was translated by the MCC and represents a stellar example of the type of written resources the programme could provide for the benefit of many organizations and groups.

This aspect of resource material development could be combined with the development of learning toys, another area in which substantial improvement was noted. The children now 
have a much wider variety of colourful wooden toys, including furnishings for doll houses and spindle boards with rings. Wooden puzzles continue to be popular and the evaluator was greatly pleased to see the addition of one containing a map of Afghanistan. An acceptability-index would be interesting, especially regarding those toys the children reject.

Toys of any variety were practically unknown in prewar rural Afghanistan and a monotonous sameness characterized what was available. The toys at the MCC are very simply made. Rag dolls come from families within Kahi; stuffed balls and animals are supplied by the work-study students at the Peshawar ECETP; many wooden toys are made by Afghan roadside carpenters in Peshawar. Might it not be possible to produce smell manuals on toy production, with simple drawings, patterns and transfers so thet local manufacturers, including women, could set up businesses to broaden distribution?

Art and paper cutting is thoroughly enjoyed as previously. There is still a great reliance on the use of stencils, but more free-hand art work on a wider variety of subjects was noted. Several children presented folded paper (oragami) boats and flowers to the evaluator who was delighted to share in their creative pride.

For the older girls the introduction of knitting was an exciting new development. Bonnets and bootees further child-to-child interactions as well as health objectives. 
The play area at Kahi is severely restricted as the centre stands within the walls containing the health units. Because of the conservative attitudes of Kahi's population and the strong influence of their religious leaders, it has not been possible to implement plans for an outside play area. It is interesting to note, however, that the argument used by the religious leaders in objecting to the playground centered around the fact that it would detract from the children's learning experiences, a clear indication of their general approval of MCC activities. This is a distinctly positive development. Objective 3: care of younger siblings

Recognizing the central role of preteens in caring for younger children discussed in the first evaluation, numbers of child-to-child activities emphasizing development play opportunities and lessons in health, hygiene, child-care, nutrition, oral rehydration therapy and other health-related topics have been introduced. No practical demonstrations of treatments for eye-nose-ear care, simple wounds, insect bites, heat rash and other simple childhood ailments were noted. This would be additionally beneficial as noted in the earlier evaluation.

It was noted with satisfaction, however, that the staff largely limit themselves to supervisory/facilitory roles, leaving it to the children to introduce newcomers and younger children to play/learning activities. 


\section{Objective 4: reinforcement of cultural identity}

Furtherance of this objective continues. Particularly noteworthy are the adaptations of Islamic teaching methods used in other Islamic countries. These have also been shared with ARIC and constitute an important contribution to overall assistance programming. These translated Dari/ Pashto texts not only promote the ethics and precepts of Islam as they apply to children, but emphasize the practical health and hygiene practices included in the Islamic texts.

Rural Populations: Shin Dand, opened March 1990

Early in 1989 renewed military octivities inside Afghanistan created a distressing flow of new refugees to Pakistan where several new camps were hurriedly established. One is located at Shin Dand near the large administrative town of Kohat, about an hour east of Hungu. Although Shin Dand means Green Lake, the area is an arid wasteland with severe water problems.

The population of Shin Dand $(15,000)$ contains many households originally settled around large Afghan towns such as Jalalabad. The town-village links were strong and frequent interactions lent a certain openminded receptiveness to these village populations. There seems also to be more balance between the religious and civilian leadership. 
The Facility. Designed by the MCC Programme staff and built of mud by resident Afghan masons at one-half the cost of estimates provided by the IRC construction unit responsible for the Kahi facility, the Shin Dand MCC is hardly distinguishable from neighbouring residences. I-shaped, it is bounded by its own wall and stands in the vicinity of, but distinctly separated from, the health units and a large tented-boys school. A GOP/UNHCR tented-girls primary school with an enrollment of 200 originally stood near the MCC but it was recently shifted because of bureaucratic delays in providing it with a protective wall.

The Shin Dand MCC facility is thus culturally compatible with the community in many different ways. The interior is not whitewashed, but light end good ventilation is provided by a series of windows; the decor utilizes flowered plastic matting, posters on health subjects and festoons of varicoloured paper pennants in bright orange, purple, green and yellow strung out fan-like above the doors and windows. It is very cheerful, but also very simple.

Even so, objectors claim that it is "too good for children" and resembles a cinema. This is an improvement, however, over similar complaints that the Kahi MCC was a house of prostituis. tion!

Participants. Average attendance fluctuates around 70 and initially there appear to be more girls than boyø. Because of the near-by schools an attempt is mode to keep closer 
track of ages; both boys and girls of school age are turned away. The dejection of those rejected is painful to see. Exceptions have been made in the cases of a few girls who must care for young siblings and cannot attend school as a regult; during the holidays some school girls attend.

Bince the need for registering ages is acceptible, this offers the possibility of developing a system for collecting background family profiles not now available at Kahi. This would be a valuable development. Staff. The 2-member staff was recruited from Shin Dand. These two gisters are from Jalalabad where they attended highschool and their work at the MCC is wholeheartedly supported by their father, a one-time government functionary. At one time it was thought that the Shin Dand population might contain a good number of such women with leadership qualities and potential, but to date there is no overt evidence of this.

Nevertheless, these two women represent the type of women ideally suited for MCC training if rural programmes are to be included in future planning. Their development and training should be carefully pursued. One sister is married with seven children, three of whom are in the MCC programme; two are in school. The eldest daughter, however, has been prohibited by her father, an unemployed laborer, from attending school because she has passed 
puberty. The fact that such an attitude persists even in this family with members who view education as a valued commodity, illustrates the complexities and difficulties which must be anticipated in future planning.

The second sister exemplifies the human tragedy of this war. She was widowed only three months after her wedding.

Both women have a natural way with children and they have created an atmosphere that is as congenial and pervasively cheerful as that at Kahi. Neither of the women were given more than rudimentary advanced training, but the Project Manager guides them as their work progresses. Activities

The activities at Shin Dand mirror those of $K_{a h i}$, being both flexible and structured, emphasizing participatory learning experiences and child-to-child play/learning activities. Children who perform well are rewarded with generous rounds of clapping, an innovation which was quite styftling for applause is not a usual audience reaction among Afghans. Several small children evidence extraoridnary leadership potential.

Objectives 1 thru 4 as discussed under Kahi are being met with the same success and reservations, with notable exceptions.

Because the facility is walled, the courtyard provides 
a private space where vigorous games are played with great merriment. This offers an opportunity for collecting and recording more children's games. A handwritten Dari manuscript presented by the MCC Programme to ARIC has attracted considerable interest but the production could be much improved. As with collections of children's stories and toys, such research would provide a valuable dimension to a neglected aspect of child development in Afghanistan.

I cannot resist including a personal aside. These children provided a significant insight into the question of headcovering for Muslim women, a subject which has lately excited so much heated discussion within the Muslim world. where women moving in public without headcoverings have been cited as being "bad" Muslims and the conservative hejab has gained in popularity as a result. Elsewhere, Muslim women in western countries endure harassment in the workplace and in educational institutions because they insist on keeping their hair covered. By watching the children at play in Shin Dand it was very evident that this behaviour is learned at a very early age. Even toddlers constantly secured sliding headscarves and the finesse with which trailing scarves were kept in place during energetic running games and roughhousing was a marvel to behold.

The children's games provide amusement for all, including audiences of smiling women seated against the courtyard 
wall. Recess over, numbers of these women follow the children inside. They may well provide a nucleus for sustained attendance. It is still too early to tell.

Reading and arithmetic, not yet introduced at $\mathrm{Kahi}$, are an important part of Shin Dand's curriculum. Blackboards hung low below the windows provide easy access for little children and are an attractive addition to the decor.

During Islami classes, Shin Dand children are taught to practice the correct postures during prayer.

Objective 5: interactive play/learning for mothers

This original objective at Kahi had to be set aside for reasons explained in the first evaluation. Although it is yet unclear whether it can be fully realized at Shin Dand, the signs are more hopeful.

The community does not seem to object to women attending the MCC but the women themselves have yet to fully comprehend the value of the concept of mother-child interactions in such a setting. Those who came at first expected some compensation. Other programmes sometimes entice women by giving out soap and other health aids and these women seemed genuinely perplexed about what was expected of them.

As discussed in the first evaluation, the concepts of the MCC Programme are new and the theories behind early childhood development are ...: beyond the comprehension of most non-litèrate village women. This certainly does not mean 
that these women are incapable of learning the values or of eventually participating in such programmes, but it does mean that time and patience will be needed to convey the message. As mentioned above, the nucleus: of a. group may already be forming. It is expected that it will grow.

\section{Urban Programme: Early Childhood Education Training Project} (ECETP) Peshawar, opened April 1989

The ECETP developed in response to expressed needs for providing unavailable educational opportunities and activities for children whose normal socialization had been adversely affected by war and life in exile. Concurrently, women professionals expressed the need for continuing careers and upgrading educational skills.

Participants. The primary users are urban-based Afghan women interested in acquiring or upgrading skills in early childhood development. Children of students and staff, as well as a few outside families, attend a preschool where materials are tested and students and staff gain practical experience. Other organizations with related profects also benefit from the written resource and learning aids produced by the ECETP.

The number of students included in the formal classwork and work-study activities add up to 24 a year, divided between two courses with 12 students each; 25 children attend the preschool each term. Again, no background profiles have been complled on the participants. 
Staff. The profesaional teaching staff of four have had prewar experience in Afghanistan in childhood education and kindergertens. The support staff consists of an administrative assistant, a translator, and an assistent coordinator (an expatriate). The position of Programme Coordinator was occupied until recently by an expatrlate; in March 1990 the position was taken over by an Afghan professional with many years experience in the field of education and administration. The Programme Coordinator is responsible for programme development, supervigion and management of all MCC projects, in Hungu, Kohat and Peshawar.

Activities, Objective 1: training and resource centre

Curriculum development and administrative organization a.t the ECETP seem well in place. Perhaps the most important concept being taught is the distinction between child care and childhood educational development.

The need for child care has been recognized ever since women began to seek employment in the refugee environment. Numbers of organizations provide child care facilities and in many cases women consider them a prerequisite for employment, but these services are regarded primarily as child depositories and few go much beyond the baby sitting level. Nevertheless, they are oftentimes referred to as preschools and the meaning of early childhood education remains confused. The concepts taught by the ECEIF are en importint innovation, but, they are not widely appreciated. If ECETP 
graduates are to attain the status due them, it is important that the distinction between child care and early childhood development is made known throughout the community because simple child care is at the moment a much undervalued occupation.

The question of status cannot be underestimated for it affects all sectors. Women anxiously seeking employment have refused positions they considered less prestigeous than the ones for which they were trained. Once an office manager, never a receptionist, is an attitude which is hard to change, particularly if family pressure upholds it. This is particularly evident among the proto-elites who now atrive to be more like the elites remembered from the idealized good times of prewar years.

On the other hand, a lack of commitment also plagues programme developers and has to be taken into consideration in long-term planning. There were notable exceptions, of course, but many women working in government offices in Kabul before the war were lackadaisical in their attidues toward their jobs, especielly regarding promptness and regular attendance. Family came before work, and it was not considered important to give notice before taking time off for personal family requirements. The concepts of unpaid overtime or added responsibilities without compensation were generslly considered unreasonable. Increased benefits, however, were, assiduously pursued. 
Many of these same attitudes effect the work of women in Peshawar and the constant need to guard against sliding back into old work habits hampers attempts to introduce innovatory alternative approaches. One may then consider questions of motivation. Can individuals be counted on to maintain interest in long-term development beyond short-term job opportunities?

Tied to this is the need to provide directional input for planning. The ECETP undertook three mafor activities in this regard: a seminar in which women were asked to discuss their perceived roles, now and in the future; a proposal writing workshop; 8 registry of projects designed by women. Space does not permit a thorough analysis of the results, but it is evident that there is no concise focus in women's thinking about project development. Two models predominated. One was the classic old-style institution which relied heavily on formal lesson plans and centralized structured administrative procedures. The other was built on observed examples of foreign organizations operating in Pakistan which emphasize large programmes replete with expensive technology. Basing their views on these examples women have been clearly legd to believe that small projects are unacceptable and that it is useless to think small.

The BCETP semingrs and workshops have made a significant beginning in encouraging women to reorient their thinking in terms of long-term goals and objectives, setting priorities, 
realistically ossessing resources and identifying beneficiaries. This is an aspect of programme development which warrents more attention.

Objective 2: development of written resources and learning aids

The ECETP is one of a few organizations which have produced written rescurce materials in Afghan languages, and they lead in designing and producing educational learning aids for children. It is hoped that these efforts will be expanded. It is also suggested that their research in toy design be utilized in other practical ways, such as supporting independent toy makers in economically viable business ventures which may continue after repatiration. Encouraging women in such ways would be of great value, for the present and for the future. Objective 3: support to rural MCC profects and related organizations

This objective has been commendably met in supplying teaching materials and learning aids to the MCC rural projects. Though tenuous, the links with related organizations are a good beginning. Reciprocal exchanges between organizations is a facet of Peshawar's humanitarian services which has been universally limited and the ECETP provides a positive example, but it could be strengthened and broadened to everyone's benefit. And here one must draw a distinction between cooperation and coordination. Coordination has many problems and is not being recommended in this context. The ECETP, however, is ideally constituted to act as a 
catalyst, a centre for coherent groups working for the same goals.

\section{Objective 4: outreach support}

There is a real need for organizational support for small, home-based, low-cost Afghan-administered projects and especially for those which function within accepted women's networks.

This objective at the MCC Programme was thwarted through lack of funding and sufficient full-time advisory and monitoring personnel. It warrents continued consideration, nonetheless, for home-based, economically self-sustaining projects will meet an added valued objective of encouraging women to achieve a sense of personal fulfillment while contributing to family welfare. Being independent and home-based these projects would be culturally acceptable and overcome a number of the male ideological objections to the employment of women by foreign organizations.

Another advantage would be in meeting the real problem of providing productive employment for ECETP graduates. Training for the sake of training alone is hardly a desirable objective. Some responsibility for enabling trainees to utilize their newly acquired skills should be assumed.

To be successful, such projects would need not only to utilize skills in childhood education development, but include expertise in management and financing. 
MANAGEMENT DEVELOPMENT

The uitimate aim of any project should be to enable participants to assume decision-making and management responsibilities; to set their own priorities and devise systems for meeting these priorities.

As long as programming remains in the hands of outsiders, women will not take responsibility; even the thought of assuming responsibility will not arise in many incidences so long as the option to rely on others exists. Given the history of the previously discussed attitudes toward responsible work habits, this will take patience, direction through in-service training, and strong supervisory support. The MCC Programme provides examples of such efforts.

At all three MCC programmes the female management staff has been encouraged to participate in planning for short-term and long-term development, write monthly reports, submit monthly accounts, maintain facilities, oversee orders and supplies, train new staff, develop course content, and organize work schedules, in addition to their teaching duties.

While encouraging such independent actions, the existence of a strong support system remains a key. This was evident throughout the MCC development as responsibilities and decision-making was gradually transferred to the Afghan staff. This entails passing on such techniques as needs assessment, the identification of priorities, decision-meking management, proposal writing, budgeting, report writing, and long-term 
planning. Few Afghan women have had the opportunity of acquiring these skills and this aspect may prove to be among the more important contributions that can be made. It can not be reported that the transition at the MCC is totally complete in all these respects, but a beginning has been made. Knowledge of how to access funding sources is another important learning experience which is hampered by restrictions on women's movements. Still, setting up regular liason procedures and exposure to upper manggement can be managed if approached with imagination.

Just as important, perhaps, is the need to convince donor organizations that it is essential to foster independent management and accept possible liabilities. Some of the most valuable lessons come out of initial failures; to know why a programme did not work is to gain insight into what can succeed. The most dynamic programmes are those which dare to experiment with a multiplicity of approahces. To do this, how ever, women must feel secure in the knowledge that they will be supported if they inftiate innovatory programmes without worrying about being abandoned. Allied to this is the need to recognize those willing to assume responsibility through commensurate salaries and promotions. Motivation can be as important as any skills in the creation of imaginative programme development. 
MOVEMENT TOWARD WHAT GOAL

In today's confused and difficult atmosphere it is hard to define future goals for the challenges which lie ahead. The composition and style of a political solution is uncertain, making any discussion rudimentary and speculative. The crucial question, therefore, must relate to the relevance of basic concepts, regardless of how larger solutions are structured.

The answer, admittedly based on intuitive judgement, must obviously be, yes, the MCCs are relevant, because their overall goal is to provide all-round development from early childhood. Children represent the future and their optimal physical, emotionel and social development is therefore inextricably enmeshed with the well-being of the totality of the nation.

Specifically, some cultural patterns can perhaps help orient projects more toward compatible implementation. Initially, models associated with MCC-type projects will probably be more appropriate for urban settings. Nevertheless, if current thinking emphesizing district and provincial development orientations materialize, the possibilities for rural projects may present themselves.

After repatriation what opportunities will exist in the rural areas? If no mejor changes occur, continued traditional child socialization patterns requiring children to shoulder household responsibilities from a very early age and leaving 
them little time for learning away from home will predominate. Then it may be predicted that there will be little interest in inṣtitutional provisions for young rural children because the traditional child socialization processes are wellestablished and well-adapted to reeds.

If, on the other hand, a service-oriented infrastructure is put in place on the lowest administrative levels and economic necessity encourages women to participate in locally. based development projects, early childhood education facilities at schools, health units and workplaces could well enhance attendance. For instance, in the past, the need for children to remein at home to care for younger children was said to account for low school attendance. If MCCs were established in connection with school:, might not this arguement become obsolete? Similarly, if work opportunities for women are established within communities, more women will need to seek training at provincial centres where MCCs would be most appropriate. In addition, efforts to include early childhood education in the curricula of training institutions would be a distinct service, be they in medicine or education. Since these possibilities exist, the troining of personnel and the development of learning meterials appropriate for rural. populations can be viewed as a valuable long-term goal. If adopted, however, advocacy roles by future associates would become all-important as the potential of early childhood 
education is probably beyond the ken of the majority of development planners. Perhaps it would be well to start now in establishing links with organizations operating crossborder programmes. I suspect initial discussions would be tentative and probably frustrating, but this is how the process of advocacy usually begins.

The essential point here is that any MCC programme must not be set up in isolation. It must be made an integral part of community development in which all sectors work together - as well as being mede a part of the total sustained environment in which local groups take part in addressing needs and programming decisions so that projects reflect the communities of which they are a part.

If one relates all this to Kahi, it must be said that programme decisions are not at present being made by the users. Only at Shin Dand has it been possible to identify and ... train. : core personnel from the community. This is a model which should serve as an ideal goal. It will not be easy, but the Shin Dend staff proves that capable women are there; the question is, how to find them?

Judging from the experiences gained from the work of the ECETP, urban women are more aware of the effects of war and exile on children and the long-term need to provide normalized learning activities compatible with Afghan culture. Even language skills are endangered because there are no centres devoted to Dari and Pashto language training and children, as 
well as young adults, are learning foreign languages better than their own.

But what are the general perceptions of MCC programmes within the community at large? On reading some of the reports written by staff and trainees one senses a lack of clarity regarding the meaning of early childhood education and the distinction between it and preschool or agency care facilities. The fact that early childhood education can be used not just for learning but as a crucial period for shaping, supporting and enhancing relations between parents and childran, and betwen children and the community, seems not adequately understood.

In fact, the function of children and parents working and learning together is not a typical Afghan occurance. Neither is seeing young children's needs as paramount appreciated, particularly by males who tend to find the concept irrelevant and of low priority.

The entire issue of parent involvement in education is novel - and to some, suspect. Traditionally education was the responsibility of the mosque, then the government became involved and eventually the very institution of education came to be depreciated by those who saw it as a vehicle for the introduction of atheism, communism and westernization. Even today the day-care centres and kindergartens established in Kabul under Soviet auspices before the coup d'êtat are vilified as institutions designed to usurp the family's para- 
mount role in child socialization, thereby jeopardizing Afghan culture.

These feelings have cooled somewhat over the years, but as we see today they can easily be fanned into action. Nevertheless, the three most important factors to be noted are that 1) 'women's primary concern is for their children, 2) women hold education for children in high regard, and 3) women have much influence in the home regarding children.

Prog rammes like the ECETP will, therefore, be highly appreciated by large groups of women. Programmes designed to improve educational and developmental chances of young children should be promoted in the context of family and community, focusing on intensive training with concomitant development and production of learning materials of all sorts.

The target population would include women from all sections of society, at various educational levels, but it should be kept in mind that lower-income urban women will be especially vulnerable and liable to be overlooked. They will perhaps be the group most in need of these types of opportunities.

Therefore, one may conclude with the observation that the Mother-Child Centre Programme for Afghan Refugees has established programmes which could provide an excellent base for future innovative, imaginative programming. 


\section{MAJOR SUGGESTIONS}

$\underline{\text { Page }}$

- background profiles: Kahi, Shin Dand, ECETP

$7,14,18$

- motivation studies on attendance

8

- house visits

8

- further development of visual learning materiels

- further collection/production of folklore resource materials

- further development of learning toys

- manuals for toy production

- practical health demonstrations

- identification/troining of personrel for rural areas 14

- further collection/production of resource material on games

- directional input for training/1ntegratedplanning 21 , 28

- further design/production. of written resources and learning aids

- reciprocal cooperative efforts with related programmes

- small, home-based outreach projects

- employment of ECETP graduates

- further decision-making/ management skills development

- access funding and upper management

- advocacy

- commensurate salaries and promotions

- provincial training institutions inside Afghanistan 27

- early childhood education curricula after repatriation 27

- lower-income urban women after repatriation 